\title{
THE ROLE OF DISPERSION MEDIUM ON NANOPARTICLE AGGREGATION AND SIZE IN BIOLOGICAL SYSTEMS
}

\author{
1, ${ }^{2}$ Tereza ČERVENÁ, ${ }^{1}$ Andrea RÖSSNEROVÁ, ${ }^{1,3}$ Táňa ZÁVODNÁ, ${ }^{1}$ Kristýna VRBOVÁ, \\ 1, 2 Jitka SIKOROVÁ, ' Jan TOPINKA, 'Pavel RÖSSNER, Jr. \\ ${ }^{1}$ Institute of Experimental Medicine, Czech Academy of Sciences, Prague, Czech Republic, EU \\ ${ }^{2}$ Charles University in Prague, Prague, Czech Republic, EU \\ ${ }^{3}$ VSB-Technical University of Ostrava, Ostrava, Czech Republic, EU
}

https://doi.org/10.37904/nanocon.2019.8704

\begin{abstract}
The use of nanomaterials (NMs) in different areas has been rising for more than a decade. Along with this growth, there is visible development of different testing tools and approaches for measuring the actual size of nanomaterials in biological systems. Test conditions during in vitro toxicological assays are different from the standard conditions under which nanomaterials are characterized and careful evaluation of results is needed. The unique properties and range variety of NMs require the close look how the NMs behave in different dispersion medium over time. In this study we present the results of five types of well-characterized NMs (TiO2: NM-101 and NM-103; SiO2: NM-200; Ag: NM-300K and NM-302) of specific size and shape. The hydrodynamic size and Zeta potentials in suspensions were measured using a dynamic light scattering technique (DLS) (Zetasizer Nano ZS, Malvern, UK). The DLS method is suitable for spherical particles; nevertheless, all samples were measured in order to obtain a rough insight into agglomerate formation in the medium. NM300, NM302, and NM200 aggregated rapidly in the media, thus the cells would be most likely exposed to settled big aggregates then small clusters or individual particles. More stable NMs (NM100 and NM103) showed slight grow along with cultivation time or concentration corresponding to cluster formation. Cells exposed to those NMs would be in contact with small clusters and aggregates of NMs. Measured zeta potentials fluctuated around the stability limit corresponding to observed aggregation. This work was supported by the MEYS CR (LO1508).
\end{abstract}

Keywords: Nanomaterials, NMs, DLS, aggregation

\section{INTRODUCTION}

The tremendous increase of nanomaterials (NMs) application has been witnessed during the last decade in many areas and massive numbers of consumer products contain NMs. Also, the number of registered NMs increased rapidly according to current Nanowerk Nanomaterial Database ${ }^{\mathrm{TM}}$ to almost 4000 (http://www.nanowerk.com/).

The nanomaterials (NMs) have been defined as "a natural, incidental or manufactured material containing particles, in an unbound state or as an aggregate or as an agglomerate and where, for $50 \%$ or more of the particles in the number size distribution, one or more external dimensions is in the size range $1 \mathrm{~nm}-100 \mathrm{~nm}$ " (EU recommendation number 2011/696/EU) [1]. Due to the possible exposure of humans via a large number of consumer products and the evidence showing that exposure to nanoparticles (NPs) has various toxic effects, the interest of toxicologists in these materials has increased.

The development of appropriate in vitro protocols is a challenging issue and expanding range of NMs led to high demand for proper testing methods. One of the issues is rapid changes in physicochemical properties (shape, size, reactivity, surface area, etc.) after dispersion in biological fluids. Choosing the optimal 
methodological variant of the assay and timing of the exposure experiment is a major task of the toxicology testing.

Dispersion of NMs in liquids cause the well-known effect of the formation of protein coating around nanoparticles (Figure 1). This protein corona is a key molecular event, which strongly influences the biological response in nanotoxicological tests. The corona is composed of 'hard' and 'soft' components [2]. The hard corona represents inner stable layer tightly bound to the particles and the soft corona is a looser layer on top of the hard corona. The assayed particles are different in composition and surface chemistry than those originally synthesized [3].

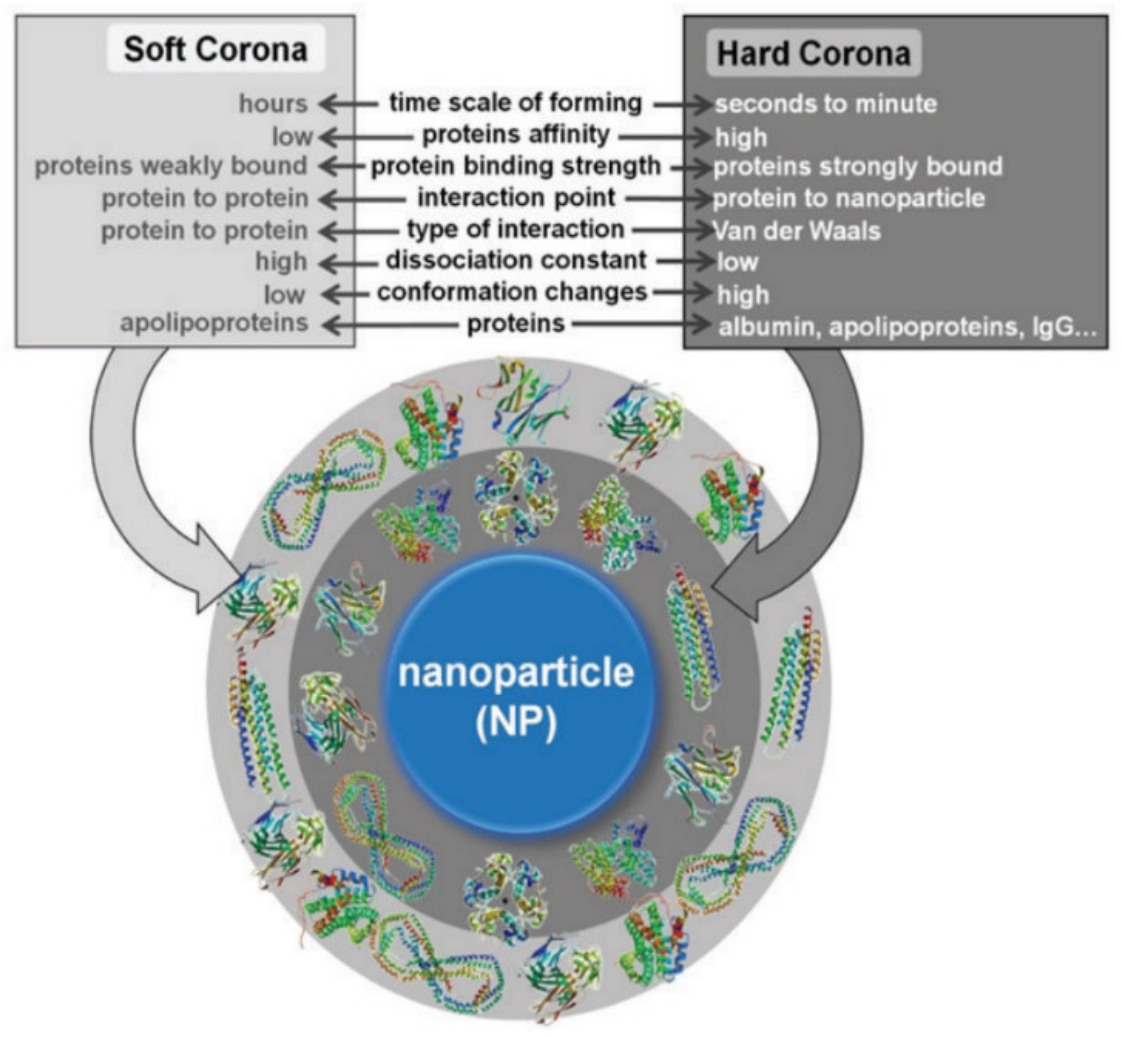

Figure 1 Protein corona formation on nanoparticle core. Different composition and surface chemistry change NMs properties. Figure and figure legend reproduced from reference [4].

It has been repeatedly shown, that different composition of dispersion medium can largely affect the formation of the protein corona. Dynamic light scattering (DLS) analyses were done on gold nanoparticles suspended in two widely-used cell culture medium (Dulbecco Modified Eagle's medium (DMEM) and Roswell Park Memorial Institute medium (RPMI), both supplemented with fetal bovine serum). DMEM caused the formation of a larger and time-dependent protein corona, although RPMI shows different time dynamics with lower protein coating. No formation of agglomerates/aggregates in the two media was found by DLS and this finding was also confirmed by TEM analyses [5].

Another study using golden nanoparticles $(10,25,50$, and $100 \mathrm{~nm}$ in diameter) confirmed the previous results. Size distributions of gold nanoparticles suspended in deionized water were similar to what the manufacturer stated. DMEM supplemented with fetal calf serum led to the formation of complexes around $100 \mathrm{~nm}$, regardless of their nominal sizes. The influence of supplementation by fetal serum was proved by DLS in DMEM that was without serum. The results indicated gold nanoparticle agglomeration and size of the agglomerates was found to increase with increasing nanoparticle concentration [6]. 
In this work, we present data from five types of well-characterized NMs $\left(\mathrm{TiO}_{2} \mathrm{NM}-101\right.$ and NM-103, $\mathrm{SiO}_{2} \mathrm{NM}-$ 200, Ag NM-300K and NM-302) differing by their properties, including size, shape, or e.g. dimension of aggregates.

\section{METHODS}

\subsection{Nanomaterials preparation}

Five types of NMs differing by their characteristics were involved in genotoxicity experiments: (i) $\mathrm{TiO}_{2}$ [titanium dioxide - anatase form, primary particle size $5 \mathrm{~nm}, \mathrm{NM}-101$ (Joint Research Centre)]; (ii) $\mathrm{TiO}_{2}$ [titanium dioxide - rutile form, primary particle size 20-100 nm, NM-103 (Joint Research Centre)]; (iii) $\mathrm{SiO}_{2}$ [synthetic amorphous silicon dioxide produced by precipitation, particle size 10-20 nm, NM200 (Joint Research Centre)]; (iv) Ag [silver with prevalently round shape, particle size $<20 \mathrm{~nm}$, NM-300K (Joint Research Centre)] and; (v) Ag [silver with rods shape, particle size 100-200 nm width, 5-10 $\mu$ m length, NM-302 (Fraunhofer)]. The preparation of NMs for genotoxicity testing was performed according to instructions of the generic NANOGENOTOX dispersion protocol (www.nanogenotox.eu).

Briefly, $15.36 \mathrm{mg}$ of NMs were weighed in glass vials using a microbalance (RC210D, Sartorius, Germany). NMs were then pre-wetted with $30 \mu \mathrm{l}$ of $95 \%$ ethanol and diluted in $5.970 \mathrm{ml}$ deionised water ( $\mathrm{diH} 2 \mathrm{O}$ ) containing $0.05 \%$ bovine serum albumin (BSA). If the NMs were available in a dispersion form, the amount of used dispersion was calculated to correspond to $15.36 \mathrm{mg}$ of dry NMs. The NMs dispersion was vortexed for 2 minutes before manipulation. In total $6 \mathrm{ml}$ suspension of NMs with $0.05 \%$ BSA is called batch and had a concentration of $2.56 \mathrm{mg} / \mathrm{ml}$. Batches were sonicated (400W and $10 \%$ amplitude) by an ultrasonic homogenizer (S-450d, Branson, USA), equipped with a standard 13-mm disruptor horn for 16 minutes in an ice bath to prepare batch suspensions at a concentration of $2.56 \mathrm{mg} / \mathrm{ml}$ [7]. The suspension was gradually diluted by medium to reach final concentrations of 25,10 , and $1 \mu \mathrm{g} / \mathrm{ml}$ for NM101, NM103, and NM302 or 5 , 2.5 , and $1 \mu \mathrm{g} / \mathrm{ml}$ for NM300K and NM200.

\subsection{DLS and Zeta potential}

The hydrodynamic size in suspensions was measured using a DLS (Zetasizer Nano ZS, Malvern, UK). Hydrodynamic size (Z-Avg), and polydispersity index (PDI) were determined according to the ISO method ISO13321:1996, and its newer pendant ISO22412:2008. Batch suspensions were measured within 20 minutes after sonication. Medium suspensions were measured $0 \mathrm{~h}, 28 \mathrm{~h}$ and $48 \mathrm{~h}$ after preparation. All suspensions were vortexed before measurement. Until the measurements took place, medium suspensions were kept at $37^{\circ} \mathrm{C}$ to simulate the same conditions during toxicity testing. Sample solutions were measured in DTS0012 polystyrene cell cuvettes, stabilisation time was set to $120 \mathrm{~s}$, temperature to $25^{\circ} \mathrm{C}$ for batch, and $37{ }^{\circ} \mathrm{C}$ for diluted samples. At least 12 runs were performed per each concentration. The same setting was used for measuring zeta potentials (DTS 1070 cuvettes).

\section{RESULTS AND DISCUSSION}

DLS method is suitable only for spherical particles; nevertheless, all samples were measured in order to obtain a rough insight into agglomerate formation in the medium. As a part of our experiments, we compared hydrodynamic size (Z-avg) and polydispersity index (PDI) of NM103 diluted in filtered and unfiltered LHC-9 medium (Figure 2). This medium is characteristic for high protein agglomeration resulting in visible particles over time. Thus, it is a suitable model for testing the influence of protein agglomerates to DLS results. Only the highest concentration of $25 \mu \mathrm{g} / \mathrm{ml}$ was measurable. We observed a time-dependent increase of agglomeration in both filtered and unfiltered medium (B1 and C1; B2 and C2) and decrease in PDI when the filtered medium was used. Lover tested concentrations $(10 \mu \mathrm{g} / \mathrm{ml}$ and $1 \mu \mathrm{g} / \mathrm{ml})$ had too high PDI (> 0.7) probably due to the 
high amount of protein particles. NMs signal was lost in these samples and data is not shown. Zeta potentials did not change.
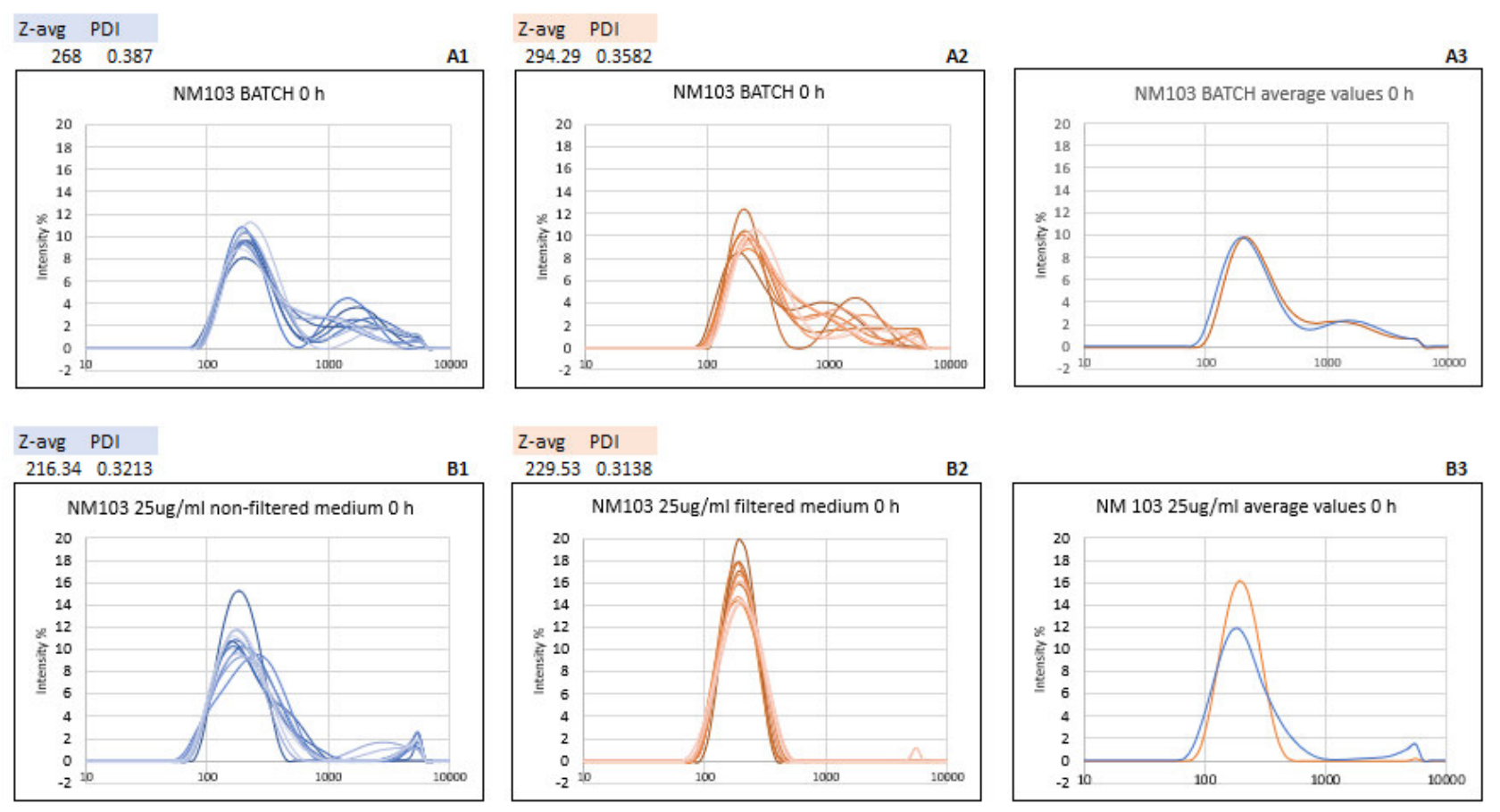

Z-avg PDI
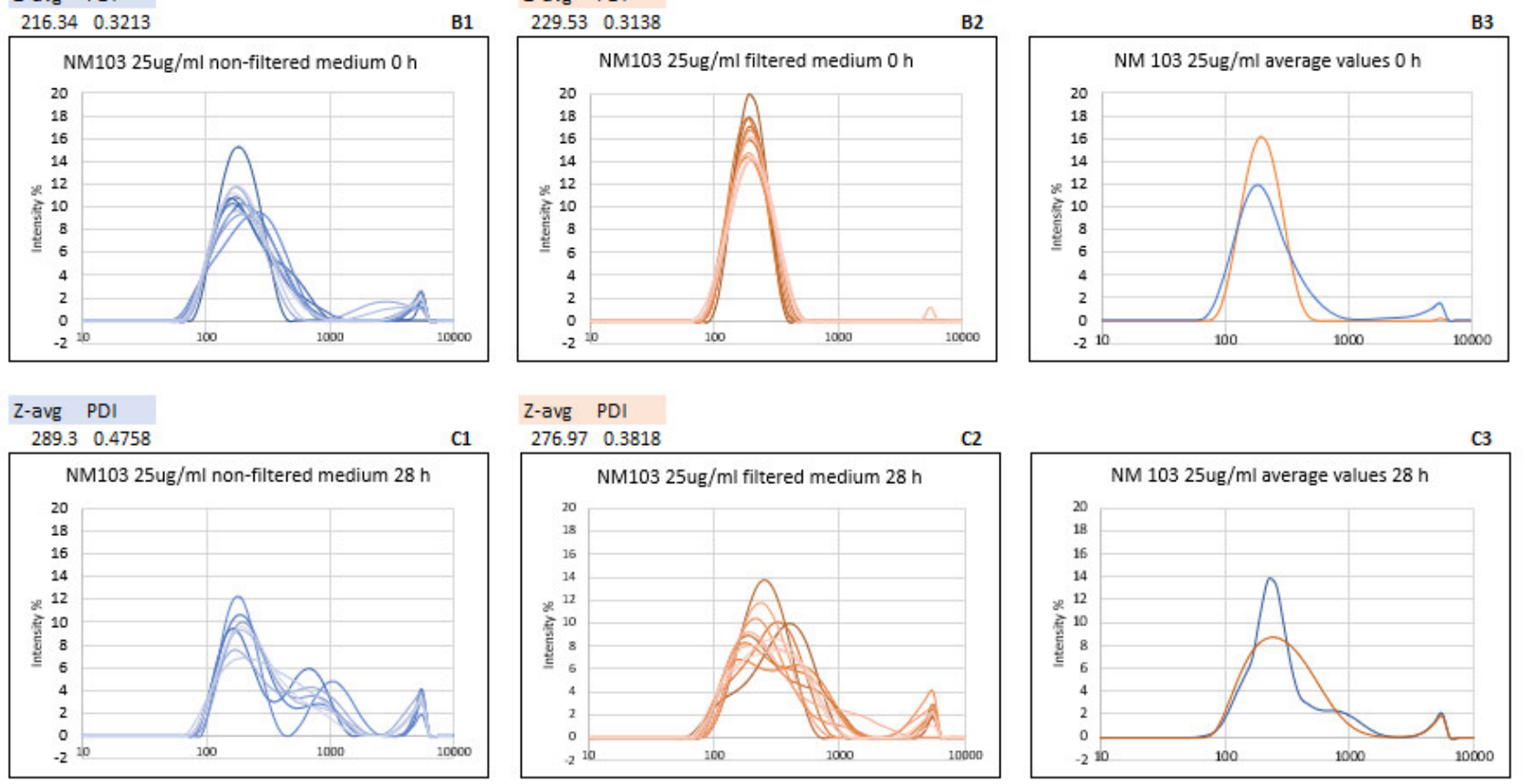

Figure 2 Hydrodynamic size of NM103 (titanium dioxide - rutile form, primary particle size 20-100 nm) in medium suspensions measured using a DLS immediately after preparation (A-B) and 28 hours after (C). Hydrodynamic size (Z-Avg), and polydispersity index (PDI) was measured in LHC-9 serum-free medium.

Another dispersion medium tested was bronchial epithelial growth medium (BEGM ${ }^{\mathrm{TM}}$ kit CC3170). Nearly all of the tested NMs (NM101, NM200, NM302, NM300) had bigger or similar Z-Avg in the compared to the batch in time zero (Table 1). After 28 hours or 48 hours, we observed an increase in size for all mentioned NMs. This observation together with higher PDI indicates the formation of aggregates in the BEGM. Only NM103 (titanium dioxide - rutile form, primary particle size 20-100 nm) did not change over time. According to the manufacturer (Malvern Instruments, 2011), the DLS measurement is suitable only for suspension with PDI up to 0.7. If the PDI is greater, the suspension is too polydisperse; NM302, and NM200 exceeded this limit in some cases. Those NMs aggregated rapidly in the medium, thus the cells would be most likely exposed to settled big aggregates than to small clusters or individual particles. More stable NMs (NM100 and NM103) showed slight grow along with cultivation time. The higher values of PDI were present mainly at $48 \mathrm{~h}$ cultivation. Cells exposed to NM100 and NM103 would be in contact with small clusters and aggregates of NMs that to large ones. 
Zeta potential for our NMs varied between -10 and $-17 \mathrm{mV}$ and did not change with cultivation time. Zeta potential between 10 and $20 \mathrm{mV}$ (above or below zero) suggests relatively stable suspension [8], [9]. Measured Zeta potentials fluctuated around the stability limit corresponding to observed aggregation.

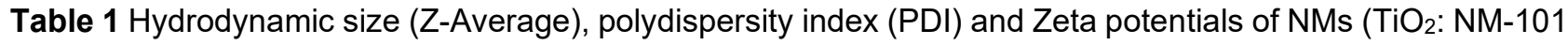
and NM-103; $\mathrm{SiO}_{2}$ : NM-200; Ag: NM-300K and NM-302) with specific size and shape measured over time. Z-Avg and PDI were measured in bronchial epithelial growth medium (BEGM ${ }^{\mathrm{TM}}$ kit CC $\neg 3170$ ) without serum.

\begin{tabular}{|c|c|c|c|c|c|c|}
\hline \multicolumn{7}{|c|}{ NM101 } \\
\hline \multirow[t]{2}{*}{ BEGM } & \multicolumn{2}{|c|}{ Z-Average (d.nm) } & \multicolumn{2}{|c|}{ PDI } & \multicolumn{2}{|c|}{ Zeta pot. } \\
\hline & avg & sd & avg & sd & & sd \\
\hline batch & 481.82 & 16.40 & 0.35 & 0.04 & - & - \\
\hline $25 \mathrm{ug} / \mathrm{ml} \mathrm{Oh}$ & 496.59 & 17.11 & 0.35 & 0.02 & -14.04 & 1.48 \\
\hline 10ug/ml Oh & 491.30 & 54.83 & 0.37 & 0.06 & -13.43 & 0.92 \\
\hline 1ug/ml Oh & 328.08 & 97.08 & 0.46 & 0.06 & -14.35 & 0.66 \\
\hline $25 \mathrm{ug} / \mathrm{ml} 28 \mathrm{~h}$ & 422.23 & 38.99 & 0.49 & 0.05 & -12.98 & 1.14 \\
\hline $10 \mathrm{ug} / \mathrm{ml} 28 \mathrm{~h}$ & 417.43 & 92.98 & 0.44 & 0.06 & -12.35 & 1.33 \\
\hline $1 \mathrm{ug} / \mathrm{ml} 28 \mathrm{~h}$ & 535.05 & 185.24 & 0.56 & 0.12 & -14.89 & 1.36 \\
\hline $25 \mathrm{ug} / \mathrm{ml} 48 \mathrm{~h}$ & 449.18 & 72.40 & 0.50 & 0.06 & -15.00 & 1.63 \\
\hline $10 \mathrm{ug} / \mathrm{ml} 48 \mathrm{~h}$ & 364.04 & 72.42 & 0.46 & 0.08 & -13.10 & 0.87 \\
\hline $1 \mathrm{ug} / \mathrm{ml}$ 48h & 1226.57 & 83.31 & 0.36 & 0.08 & -17.64 & 0.81 \\
\hline
\end{tabular}

\begin{tabular}{|c|c|c|c|c|c|c|}
\hline \multicolumn{7}{|c|}{ NM103 } \\
\hline \multirow[t]{2}{*}{ BEGM } & \multicolumn{2}{|c|}{ Z-Average (d.nm) } & \multicolumn{2}{|c|}{ PDI } & \multicolumn{2}{|c|}{ Zeta potencial } \\
\hline & avg & sd & avg & sd & avg & sd \\
\hline batch & 286.75 & 21.69 & 0.36 & 0.01 & - & - \\
\hline $25 \mathrm{ug} / \mathrm{ml} \mathrm{Oh}$ & 176.80 & 7.74 & 0.26 & 0.04 & -13.21 & 1.11 \\
\hline $10 \mathrm{ug} / \mathrm{ml}$ Oh & 179.03 & 7.69 & 0.25 & 0.04 & -11.65 & 0.87 \\
\hline $1 \mathrm{ug} / \mathrm{ml} \mathrm{Oh}$ & 173.38 & 22.29 & 0.28 & 0.08 & -11.71 & 0.97 \\
\hline $25 \mathrm{ug} / \mathrm{ml} 28 \mathrm{~h}$ & 198.70 & 10.20 & 0.26 & 0.04 & -12.12 & 0.73 \\
\hline $10 \mathrm{ug} / \mathrm{ml} 28 \mathrm{~h}$ & 184.20 & 8.92 & 0.20 & 0.06 & -12.39 & 1.38 \\
\hline $1 \mathrm{ug} / \mathrm{ml} 28 \mathrm{~h}$ & 223.65 & 69.07 & 0.26 & 0.04 & -10.90 & 1.16 \\
\hline $25 \mathrm{ug} / \mathrm{ml} 48 \mathrm{~h}$ & 203.22 & 40.72 & 0.27 & 0.05 & -13.51 & 1.38 \\
\hline $10 \mathrm{ug} / \mathrm{ml} 48 \mathrm{~h}$ & 196.69 & 12.91 & 0.25 & 0.09 & -12.70 & 0.73 \\
\hline $1 \mathrm{ug} / \mathrm{ml} 48 \mathrm{~h}$ & 201.06 & 17.45 & 0.31 & 0.06 & -11.17 & 0.79 \\
\hline
\end{tabular}

\begin{tabular}{|c|c|c|c|c|c|c|}
\hline \multicolumn{7}{|c|}{ NM200 } \\
\hline \multirow[t]{2}{*}{ BEGM } & \multicolumn{2}{|c|}{ Z-Average (d.nm) } & \multicolumn{2}{|c|}{ PDI } & \multicolumn{2}{|c|}{ Zeta pot. } \\
\hline & avg & sd & avg & sd & avg & sd \\
\hline batch & 214.07 & 5.83 & 0.30 & 0.03 & - & - \\
\hline $5 \mathrm{ug} / \mathrm{ml} \mathrm{Oh}$ & 283.32 & 53.14 & 0.03 & 0.03 & -12.98 & 1.31 \\
\hline $2.5 \mathrm{ug} / \mathrm{ml} \mathrm{Oh}$ & 196.97 & 18.18 & 0.44 & 0.03 & -12.32 & 1.32 \\
\hline 1ug/ml Oh & 169.12 & 19.18 & 0.47 & 0.08 & -11.59 & 1.27 \\
\hline $5 \mathrm{ug} / \mathrm{ml} 28 \mathrm{~h}$ & 321.40 & 59.21 & 0.55 & 0.12 & -12.95 & 1.76 \\
\hline $2.5 \mathrm{ug} / \mathrm{ml} 28 \mathrm{~h}$ & 269.07 & 97.76 & 0.61 & 0.11 & -13.54 & 1.65 \\
\hline $1 \mathrm{ug} / \mathrm{ml} 28 \mathrm{~h}$ & 305.74 & 131.54 & 0.57 & 0.09 & -18.76 & 2.31 \\
\hline $5 \mathrm{ug} / \mathrm{ml} 48 \mathrm{~h}$ & 1518.18 & 98.06 & 0.65 & 0.09 & -12.87 & 1.23 \\
\hline $2.5 \mathrm{ug} / \mathrm{ml} 48 \mathrm{~h}$ & 473.70 & 238.19 & 0.59 & 0.08 & -10.99 & 2.75 \\
\hline $1 \mathrm{ug} / \mathrm{ml} 48 \mathrm{~h}$ & 2317.11 & 581.67 & 0.97 & 0.06 & -14.85 & 1.56 \\
\hline
\end{tabular}

\begin{tabular}{|c|c|c|c|c|c|c|}
\hline \multicolumn{7}{|c|}{ NM300 } \\
\hline \multirow[t]{2}{*}{ BEGM } & \multicolumn{2}{|c|}{ Z-Average (d.nm) } & \multicolumn{2}{|c|}{ PDI } & \multicolumn{2}{|c|}{ Zeta pot. } \\
\hline & avg & sd & avg & sd & avg & sd \\
\hline batch & 75.66 & 0.81 & 0.28 & 0.01 & - & - \\
\hline $5 \mathrm{ug} / \mathrm{ml} \mathrm{Oh}$ & 92.86 & 2.51 & 0.28 & 0.03 & -11.56 & 1.07 \\
\hline $2.5 \mathrm{ug} / \mathrm{ml} \mathrm{Oh}$ & 83.38 & 1.44 & 0.31 & 0.03 & -12.70 & 1.34 \\
\hline 1ug/ml Oh & 87.35 & 28.13 & 0.37 & 0.07 & -12.43 & 1.46 \\
\hline $5 \mathrm{ug} / \mathrm{ml} 28 \mathrm{~h}$ & 208.28 & 10.34 & 0.42 & 0.02 & -12.78 & 1.53 \\
\hline $2.5 \mathrm{ug} / \mathrm{ml} 28 \mathrm{~h}$ & 121.82 & 38.25 & 0.31 & 0.07 & -13.08 & 1.59 \\
\hline $1 \mathrm{ug} / \mathrm{ml} 28 \mathrm{~h}$ & 95.78 & 8.49 & 0.33 & 0.07 & -12.29 & 1.54 \\
\hline $5 u g / m l ~ 48 h$ & 767.25 & 81.01 & 0.66 & 0.12 & -21.11 & 1.64 \\
\hline $2.5 \mathrm{ug} / \mathrm{ml} 48 \mathrm{~h}$ & 137.31 & 31.75 & 0.45 & 0.08 & -13.80 & 2.16 \\
\hline $1 \mathrm{ug} / \mathrm{ml} 48 \mathrm{~h}$ & 128.97 & 31.27 & 0.46 & 0.06 & -13.71 & 1.99 \\
\hline
\end{tabular}

\begin{tabular}{|c|c|c|c|c|c|c|}
\hline \multicolumn{7}{|c|}{ NM302 } \\
\hline \multirow[t]{2}{*}{ BEGM } & \multicolumn{2}{|c|}{ Z-Average (d.nm) } & \multicolumn{2}{|c|}{ PDI } & \multicolumn{2}{|c|}{ Zeta pot. } \\
\hline & avg & sd & avg & sd & avg & sd \\
\hline batch & 451.07 & 59.21 & 0.44 & 0.11 & - & - \\
\hline 25ug/ml Oh & 816.42 & 148.07 & 0.70 & 0.09 & -15.05 & 1.50 \\
\hline $10 \mathrm{ug} / \mathrm{ml}$ Oh & 1224.80 & 261.61 & 0.85 & 0.14 & -12.81 & 0.86 \\
\hline 1ug/ml Oh & 1305.16 & 1118.92 & 0.78 & 0.25 & -14.20 & 1.57 \\
\hline $25 \mathrm{ug} / \mathrm{ml} 28 \mathrm{~h}$ & 1094.03 & 611.39 & 0.83 & 0.16 & -13.97 & 1.04 \\
\hline $10 \mathrm{ug} / \mathrm{ml} 28 \mathrm{~h}$ & 1469.97 & 679.78 & 0.95 & 0.09 & -13.75 & 1.15 \\
\hline $1 \mathrm{ug} / \mathrm{ml} 28 \mathrm{~h}$ & 191.39 & 66.06 & 0.53 & 0.11 & -13.07 & 1.77 \\
\hline $25 \mathrm{ug} / \mathrm{ml} 48 \mathrm{~h}$ & 1456.28 & 599.52 & 0.88 & 0.12 & -14.18 & 1.80 \\
\hline $10 \mathrm{ug} / \mathrm{ml} 48 \mathrm{~h}$ & 1130.63 & 702.44 & 0.79 & 0.24 & -12.83 & 1.13 \\
\hline $1 \mathrm{ug} / \mathrm{ml} 48 \mathrm{~h}$ & 317.95 & 259.75 & 0.60 & 0.18 & -13.31 & 1.70 \\
\hline
\end{tabular}

\section{CONCLUSION}

In conclusion, our tested NMs behaved differently in two tested medium. LHC-9 medium showed problematic data validation due to the aggregation and lower concentrations were not evaluable. BEGM medium was a better option for testing our NMs. The most stable of NMs under our conditions is NM103 (titanium dioxide - 
rutile form, primary particle size 20-100 nm). As proved earlier, NMs do not behave the same in different dispersion medium over time and their nominal size determined by the manufacturer can change. The different reaction to the NMs by various in vitro models can be influenced even by cultivation medium.

\section{ACKNOWLEDGEMENTS}

\section{This work was supported by the MEYS CR (L01508).}

\section{REFERENCES}

[1] "Commission recommendation of 18 October 2011 on the definition of nanomaterial (2011/696/EU)," Off. J. Eur. Union, vol. L275, pp. 38-40, 2011.

[2] BHATTACHARJEE, S. "DLS and zeta potential - What they are and what they are not?," J. Control. Release, vol. 235, pp. 337-351, Aug. 2016.

[3] YANG S. T., LIU Y., WANG Y. W., and CAO A., "Biosafety and bioapplication of nanomaterials by designing protein-nanoparticle interactions," Small, vol. 9, no. 9-10, pp. 1635-1653, 2013.

[4] CAPJAK I., GORETA S. Š., JURAŠIN D. D., and VRČEK I. V., "How protein coronas determine the fate of engineered nanoparticles in biological environment," Arh. Hig. Rada Toksikol., vol. 68, no. 4, pp. 245-253, 2017.

[5] MAIORANO G. et al., "Effects of cell culture media on the dynamic formation of protein-nanoparticle complexes and influence on the cellular response," ACS Nano, vol. 4, no. 12, pp. 7481-7491, 2010.

[6] SABUNCU A. C., GRUBBS J., QIAN S., ABDEL-FATTAH T. M., STACEY M. W., and BESKOK A., "Probing nanoparticle interactions in cell culture media," Colloids Surfaces B Biointerfaces, vol. 95, pp. 96-102, 2012.

[7] JENSEN K. A. et al., "Final protocol for producing suitable manufactured nanomaterial exposure media," 2011.

[8] AGRAWAL Y. and PATEL V., "Nanosuspension: An approach to enhance solubility of drugs," J. Adv. Pharm. Technol. Res., vol. 2, no. 2, p. 81, 2011.

[9] BHATTACHARJEE S., "DLS and zeta potential - What they are and what they are not?," J. Control. Release, vol. 235, pp. 337-351, Aug. 2016. 